\section{NEW EUROPEAN ALERT MECHANISM HAILED}

Dental professionals are hailing the newly implemented European Alert Mechanism as it will give patients more protection from potentially unsafe practice and help improve the image of dentistry.

The system aims to make the European dental industry much more transparent, covering the whole European Economic Area (EEA). It gives regulators the power to identify dental professionals who have been banned from practising to their European counterparts.

The British Society of Dental Hygiene and Therapy (BSDHT) points towards the opportunity the system gives patients to be alerted to unsafe practitioners when having dental treatment in the UK and abroad.

President of the BSDHT, Michaela ONeill, said: 'As dental professionals, patients need to know that they can trust us to give them the best treatments we possibly can.

'We are thrilled at the implementation of this system as it allows for this to happen in a highly effective and wide reaching way, giving them much greater visibility and security when it comes to their oral health.

'I see this leading to better standards when it comes to dentistry and that means better practices and overall happier patients.'

The information which regulators will have access to includes the name, date and place of birth to help identify restricted DCPs. Alerts must also state the period that the restriction applies for and the date of the decision.

For more information on the European Alert Mechanism visit http://bit.ly/1KHEWJ2.

\section{FLUORIDATED MILK APPROVED FOR BLACKPOOL CHILDREN}

A proposal to introduce fluoridated milk to over 8,000 children in Blackpool to help reduce the risk of dental caries was approved by Blackpool Council's Executive on 18 January. The milk, which is recommended by the World Health Organisation, ${ }^{1}$ is the latest in Blackpool Council's plans to tackle poor dental hygiene amongst children in the town. Figures show that almost half of 12 -year-olds in the town have at least one decayed, missing or filled tooth - much higher than the national average of $33 \%$.

Around 400 children in Blackpool are also admitted to hospital every year to have teeth extracted under general anaesthetic, at a cost to the NHS of thousands of pounds.

Councillor Graham Cain, Cabinet Secretary for Blackpool Council, said: 'Through a number of methods such as education in schools and children's centres, as well as giving away toothbrushes and toothpaste to children, we have managed to raise awareness of the importance of oral hygiene amongst Blackpool families.

'However, where some parts of the country can benefit from fluoride naturally appearing in their daily drinking water, in Blackpool we cannot.

'What we do have is a method through the free breakfast programme that allows us to reach all primary school children as they are growing up and make the fluoride milk available to them there. The scheme will be available to all primary school children but parents will have the option to opt out if they wish.

Michaela ONeill, President of the British Society of Dental Hygiene and Therapy (BSDHT), said of the decision: 'It is great that the local council has recognised that something needs to be done to address this huge problem and taken positive action.

'Other areas with similar levels of oral health problems have already introduced such schemes and this is an opportunity to show other councils that with a small, inexpensive change huge benefits can be had.'

1. Bánóczy J, Petersen P E, Rugg-Gunn A J (eds). Milk fluoridation for the prevention of dental caries. Geneva: World Health Organization, 2009. Available at: http://www.who.int/oral_ health/publications/milk_fluoridation_2009_ en.pdf (accessed January 2016).

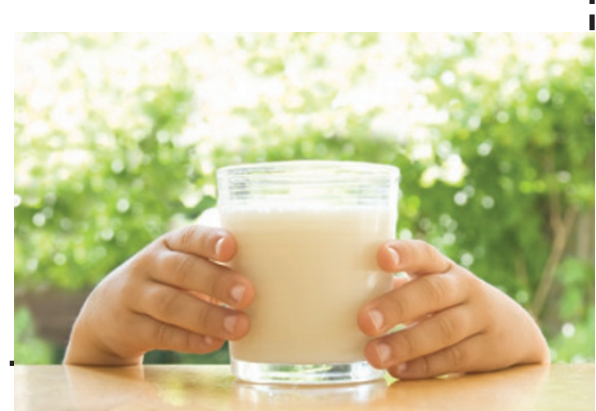

MAKE A DATE WITH YOURTEAM FOR MANCHESTER IN MAY



The British Dental Conference and Exhibition returns to Manchester on 26-28 May 2016 and will be packed with sessions and exhibitors relevant to the whole dental team.

With keynote speakers, lively panels, interactive forums, an address from a government minister, scientific lectures and smaller workshop style sessions, the conference has something for everyone. It provides comprehensive coverage of the key issues in the dental industry, and with over 130 sessions to choose from, conference attendees can grow their skillsets to achieve better patient outcomes and develop their careers.

For dental care professionals (DCPs) there will be lots of sessions on core CPD, impression taking, periodontology, treatment planning, scope of practice, implants and communication in the dental team.

Some sessions require the purchase of a Conference Pass (either one day or three day), but the remainder are free to access in the Exhibition Hall. The Exhibition is free to attend - simply register at www. bda.org/conference.

The Exhibition itself provides an excellent opportunity to meet leading suppliers and discover new ones.

Dental practice managers can benefit from the free Exhibition Hall sessions on patient marketing, complaint handling, child and adult safeguarding and team management and much more.

If you haven't done so already, register now at www.bda.org/conference. Early bird prices are available until

7 March only.

Want a free conference pass? Ask your dentist if they are a BDA Expert member. If they are, you and your colleagues may be able to come for free! 